\title{
Impacto da Covid-19 na vida de crianças e adolescentes: uma revisão narrativa
}

\author{
Impact of Covid-19 over children and adolescents lives: a narrative review
}

Impacto de Covid-19 en la vida de niños y adolescentes: una revisión narrativa

Ester Maria de Almeida Costa ${ }^{1 *}$, Anna Laura Gomes Goulart ${ }^{1}$, Victória Santos Ribeiro ${ }^{1}$, lácara Santos Barbosa Oliveira ${ }^{1}$, Amanda Aparecida Borges ${ }^{1}$, Mateus Goulart Alves ${ }^{1}$, Edna Messias de Freitas Santos ${ }^{1}$, Nariman de Felício Bortucan Lenza'.

\section{RESUMO}

Objetivo: Revisar na literatura acerca do impacto físico e psicológico da Covid-19 na vida de crianças e adolescentes. Revisão bibliográfica: aponta que com o advento da pandemia por SARS-CoV-2, houve a necessidade de novas estratégias para a garantia do cuidado e saúde das pessoas, como distanciamento social, o uso de máscaras e álcool gel, lavagem das mãos, uma nova organização e adaptação dos serviços de saúde e em geral e relativa pausa das atividades escolares por certo período. Todos esses fatores trouxeram muitas consequências à vida das pessoas no que tange a questões emocionais, físicas, sociais e laborais. Esses impactos afetaram grandemente a vida de crianças e adolescentes. Considerações finais: As crianças e adolescentes estão mais vulneráveis a psicopatologias e violências digitais e auto infligidas, ganho de peso, depressão, por conta da exposição prolongada a estressores, redução de atividades físicas, superexposição aos meios digitais e a telas. No entanto, crianças e adolescentes que já experienciaram situações de vulnerabilidade, como relações consideradas conturbadas e promotoras de desajustes emocionais com familiares, cenário de insegurança alimentar, desigualdade social e histórico de psicopatologias, foram ainda mais afetados negativamente.

Palavras-chave: Covid-19, Adolescente, Criança, Distanciamento físico.

\begin{abstract}
Objective: To review in the literature about the physical and emotional impact of Covid-19 over children and adolescents lives. Bibliographic review: show that in the current context of SARS-CoV-2 pandemic, there was a need for new strategies to ensure the care and people's health, such as social distancing, the use of masks and hand sanitizers, washing hands, a new organization and adaptation of health services and services in general and relative pause in school activities for a while. All of these factors brought many consequences to people's lives with regard to emotional, physical, social and work issues. These impacts affected enourmously children and adolescents' lives. Final considerations: children and adolescent are more vulnerable to psychopathologies and digital and self-inflicted violence, gain weight, depression due to prolonged exposure to stressors, reduction in physical activities, overexposure to digital media and screens. However, children and adolescents who have already experienced situations of vulnerability, such as relationships considered to be troubled and promoters emotional issues with relatives, a scenario of food insecurity, social inequality and a history of psychopathologies, were even more negatively affected by measures of social distance.
\end{abstract}

Keywords: Covid-19, Adolescent, Child, Physical distancing.

\footnotetext{
1 Faculdade de Medicina Atenas (Uniatenas), Passos - MG. *E-mail: estercosta437@gmail.com
} 


\section{RESUMEN}

Objetivo: Revisión en la literatura sobre el impacto físico y psicológico del Covid-19 en la vida de niños y adolescentes. Revisión bibliográfica: Muestra que con el advenimiento de la pandemia SARS-CoV-2, surgió la necesidad de nuevas estrategias para garantizar el cuidado y la salud de las personas, como distanciamiento social, el uso de mascarillas y gel de alcohol, el lavado de manos, nueva organización y adaptación de servicios de salud y en general y descansos relativos de las actividades escolares durante un período determinado. Todos estos factores trajeron muchas consecuencias en la vida de las personas en lo que respecta a cuestiones emocionales, físicas, sociales y laborales. Estos impactos afectaron enormemente la vida de niños y adolescentes. Consideraciones finales: Los niños y adolescentes son más vulnerables a las psicopatologías y la violencia digital y autoinfligida, el aumento de peso, la depresión debido a la exposición prolongada a factores estresantes, la reducción de la actividad física, la sobreexposición a los medios y pantallas digitales. Sin embargo, los niños y adolescentes que viven en situaciones de vulnerabilidad, como relaciones consideradas problemáticos y promotores de desajustes emocionales con familiares, escenarios de inseguridad alimentaria, desigualdad social y histórico de psicopatologías, fueron aún más negativamente afectados.

Palabras clave: Covid-19, Adolescente, Niño, Distanciamiento Físico

\section{INTRODUÇÃO}

O coronavirus 2 da síndrome respiratória aguda grave (SARS-CoV-2) surgido na cidade de Wuhan, China, espalhou-se rapidamente por todo o mundo. A família dos coronavírus podem causar vários sintomas, a exemplo de tosse, febre, dificuldade de respiração e infecção pulmonar, em especial pneumonia (SANCTIS V, et al., 2020).

A transmissão se dá de pessoa para pessoa, principalmente por meio de gotículas de saliva, tosse e espirros. Em março de 2020, foi declarado estado de pandemia, a qual é a disseminação mundial de uma nova doença, que deixa de afetar apenas uma região e passa a se espalhar por diferentes continentes. Para tentar frear o avanço da doença, inúmeras medidas foram tomadas, entre elas uso de máscara, lavagem das mãos, uso de álcool em gel e o distanciamento social. Esta última medida consiste em um conjunto de ações que visam o afastamento das pessoas a fim de evitar a propagação de uma doença facilmente transmitida (AQUINO EML, et al., 2020).

Apesar de bastante rígido, o distanciamento tem-se mostrado eficaz para diminuir as taxas de transmissão do Coronavírus (Covid-19). Por outro lado, a privação social imposta pelo distanciamento provoca, segundo especialistas, uma "tempestade perfeita" para a saúde mental (DANESE A e SMITH P, 2020). Nesse contexto, crianças e adolescentes são as faixas etárias mais afetadas (GHOSH R, et al., 2020; ORBEN A, et al., 2020). A princípio, crianças e adolescentes não foram identificadas como agentes majoritários de transmissão viral e adoecimento, o que resultou em menor preocupação quanto à integridade física e mental desses grupos, no contexto da pandemia (MACIEL ELN, et al., 2021).

Ainda que as crianças sejam menos suscetíveis ao vírus, possuam sintomas mais leves e melhor prognóstico, a atmosfera de tensão, a interrupção das atividades cotidianas, o afastamento das escolas e pares e a inatividade física geram consequências físicas e psicológicas severas de curto a longo prazo (GHOSH R, et al., 2020). Obesidade, ansiedade, depressão infantil, distúrbios do sono e aumento da agressividade são apenas alguns exemplos do que as crianças estão enfrentando (GHOSH R, et al., 2020; JÚNIOR PGF, et al., 2020; ALMEIDA CAN, et al. 2020).

Já a adolescência, segundo a atual discussão entre pesquisadores europeus e australianos, é o período compreendido entre 10 a 24 anos (OLIVEIRA WA, et al., 2020). Essa faixa etária é caracterizada por elevada sensibilidade social e grande necessidade de interação com pares. Jovens passam mais tempo com outros jovens do que com os próprios familiares, assim, o rompimento das relações sociais parece deixá-los mais vulneráveis a problemas de saúde mental (ORBEN A, et al., 2020). 
É importante lembrar que a pandemia causada pelo novo coronavírus é a primeira enfrentada pela humanidade no tempo online. Ainda que as redes sociais e a Internet auxiliem no não rompimento completo das interações sociais e amenizam alguns dos efeitos causados pelo distanciamento, por outro lado o maior tempo de exposição de crianças e adolescentes a essas tecnologias juntamente com nenhuma ou pouca supervisão parental podem deixar essas faixas etárias vulneráveis à violência digital e auto infligidas (DESLANDES SF e COUTINHO T, 2020). Ademais, o maior tempo de exposição a telas pode gerar distúrbios do sono, os quais predispõem ao ganho de peso e à adiposidade abdominal (ALMEIDA CAN, et al., 2020).

Estudos apontam que crianças são menos afetadas pela Covid-19, possuem sintomas mais leves e melhor prognóstico quando comparadas a outras faixas etárias. Há algumas hipóteses que podem justificar tais resultados, como: menores taxas de mortalidade pela Covid-19 em países que fazem a vacinação universal com Bacilo de Calmette e Guérin (BCG); menor prevalência de comorbidades e exposição ao tabagismo em relação aos adultos; menor expressão do receptor da Enzima Conversora de Angiotensina 2 (ECA-2), receptor em que o vírus se liga e que possibilita a sua internalização; ausência de imunossenescência (GHOSH R, et al., 2020; ALMEIDA CAN, et al., 2020). Contudo, essa faixa etária encontra-se vulnerável aos impactos psicossociais gerados pela pandemia (GOSH R, et al., 2020).

Crianças infectadas, quando sintomáticas, apresentam entre os sintomas: febre $(22,2-100 \%)$, tosse (11,1-75\%) e sintomas gastrointestinais, como náuseas, vômitos, diarreia e dor abdominal $(8,8-57,1 \%)$ (MARTINS MM, et al.,2021). Em 22\% dos casos, a diarreia pode ser o primeiro sintoma a preceder 0 diagnóstico da doença, desde que não haja sintomas respiratórios (OBA J, et al., 2020).

$O$ distanciamento social gerou ruptura abrupta na rotina das crianças, as quais passaram a sofrer com as consequências do afastamento do ambiente escolar, inatividade física, maior tempo de exposição a telas e distúrbios alimentares e de sono. Para os infantes, a escola não representa apenas um local de aprendizagem, mas também é o local que proporciona liberdade, interação com pares, oportunidade de realizarem atividades físicas e lúdicas, noções de higiene e alimentação saudável (GOSH R, et al., 2020). Com o fechamento das instituições de ensino, cerca de 1,5 bilhão de crianças e adolescentes ficaram sem escola, segundo dados da Global Education Coalition da Organização das Nações Unidades para a Educação, a Ciência e a Cultura (UNESCO) (2020). As aulas online e a impossibilidade de realizar atividades físicas ao ar livre deixaram as crianças cada vez mais restritas ao ambiente virtual (GHOSH R, et al., 2020).

$O$ excesso de eletrônicos e Internet em associação ao estresse diante da doença provocaram o surgimento de distúrbios do sono, os quais predispõem a inúmeros agravos de saúde, como ganho de peso, aumento de resistência à insulina, mau desempenho escolar, entre outros (JÚNIOR PGF, et al., 2020; ALMEIDA CAN, et al., 2020). De acordo com Danese A e Smith P (2020), a incerteza sobre o futuro, perdas traumáticas, informações insuficientes, problemas financeiros e doença mental dos pais deixam as crianças expostas a elevado nível de estresse. Como consequência, há piora da qualidade de vida; maior busca por alimentos que ativam centros de recompensa no cérebro, como alimentos ricos em lipídios e açúcar; ganho de peso e distúrbios do sono, como mencionado anteriormente (ALMEIDA CAN, et al., 2020).

Outro grande problema enfrentado pelas crianças submetidas ao distanciamento social é a obesidade (ALMEIDA CAN, et al., 2020). Em recente estudo publicado no Journal of Clinical Medicine, observou-se que o comportamento sedentário reduz a quantidade de massa cinzenta no cérebro (JÚNIOR PGF, et al., 2020). Dessa forma, entende-se que crianças com sobrepeso e obesas podem ter suas funções cognitivas prejudicadas. Além disso, no contexto da infecção por SARS-CoV-2, quadros de obesidade podem gerar aumento da necessidade de ventilador mecânico, risco de tromboembolismo, diminuição da taxa de filtração glomerular, manutenção da resposta inflamatória crônica, entre outros (ALMEIDA CAN, et al., 2020).

A interação social mediada pela Internet pode ajudar a mitigar alguns efeitos gerados pelo distanciamento, como ansiedade, depressão e solidão. Não obstante, tais tecnologias sendo usadas por crianças sem ou com pouca supervisão parental as deixam vulneráveis a violências digitais (DESLANDES SF e COUTINHO $T, 2020$ ). A busca por "material de abuso infantil" vem crescendo cada vez mais. Nesse sentido, 0 monitoramento mais rigoroso dos pais é essencial na prevenção do abuso infantil online (GOSH R, et al., 2020). 
Além da maior vulnerabilidade em relação à violência, estudos apontam que o uso excessivo de telas pode gerar baixa performance nos estudos, alterações de humor e problemas mentais ou comportamentais (MEHERALI S, et al., 2021).

Em relação aos adolescentes, os casos de violência online somam-se aos de violência autoinfligida. Um dos principais conteúdos disponibilizados pelo Youtube é o de desafios online que envolvam algum tipo de autolesão. Dentre os vídeos mais assistidos pelos brasileiros está o "Desafio do álcool em gel", o qual instiga os participantes a inalar, beber e até mesmo atear fogo no produto espalhado em uma superfície corporal. Tais atos, revestidos em tom de "brincadeira", colocam em risco a saúde e a vida dos adolescentes (DESLANDES SF e COUTINHO T, 2020).

A adolescência é um período marcado por elevada sensibilidade social e necessidade constante de interação com pares (ORBEN A, et al., 2020). Assim, a ausência de tal interação, gerada pelas medidas de distanciamento social, pode ser entendida como fator de risco para psicopatologias (DANESE A e SMITH P, 2020).

Estudos apontam como, de fato, o distanciamento social provoca efeitos únicos no cérebro e comportamento dos adolescentes quando comparados a outras faixas etárias. Pesquisas feitas com animais baseadas na privação de qualquer forma de interação com indivíduos da mesma espécie afirmam que ainda que a reintrodução ao convívio social possa amenizar efeitos negativos de curto prazo como ansiedade e hiperatividade, efeitos em longo prazo como depressão, estresse pós-traumático, aumento da agressividade, transtornos de adaptação e quadros psicossomáticos não são facilmente remediados (ORBEN A, et al., 2020).

Em um estudo realizado com uma amostra de 8079 adolescentes chineses, foi verificada elevada prevalência de sintomas depressivos e de ansiedade nessa faixa etária (ZHOU SJ, et al., 2020). Problemas psicológicos de saúde foram associados negativamente ao nível de consciência sobre a Covid-19. A prolongada exposição a estressores no contexto da pandemia desencadeia um aumento da instabilidade emocional, já vivenciada pelos adolescentes, e maior irritabilidade, os quais podem se tornar gatilhos para 0 desenvolvimento de transtornos mentais (DANESE A e SMITH P, 2020). Relações negativas com pais e irmãos ou adolescentes que vivem sozinhos podem ser ainda mais afetados pelos efeitos do distanciamento do que aquelas que possuem relações familiares positivas (ORBEN A, et al., 2020).

Em vista do que foi apresentado, a presente revisão teve como objetivo analisar dados atuais para elucidar as consequências físicas e psicológicas, a curto e longo prazo, que a vivência durante a pandemia pela Covid-19 e a infecção pelo vírus SARS-CoV-2 geram em crianças e adolescentes.

\section{REVISÃO BIBLIOGRÁFICA}

Com base nos artigos revisados, a menor prevalência de comorbidades em relação a adultos, vacinação com BCG, menor expressão do receptor ECA 2, sistema imune mais eficaz e ausência de imunossenescência podem explicar porque crianças são menos afetadas pela Covid-19, possuem sintomas mais leves e melhores prognósticos quando comparadas a outras faixas etárias (GHOSH R, et al., 2020). No entanto, por serem muito sensíveis ao estresse emocional, sofrem duramente com os impactos psicossociais da pandemia. O fechamento de escolas, falta de atividades ao ar livre e hábitos alimentares e de sono anômalos geraram rompimento na rotina das crianças e provocaram aumento de obesidade, ansiedade, depressão infantil, distúrbios do sono, aumento da agressividade, entre outros (GHOSH R, et al., 2020; JÚNIOR PGF, et al., 2020; ALMEIDA CAN, et al., 2020).

Um estudo de coorte chinês, com 1,784 crianças de educação primária da cidade de Wuhan e Huangshi apontou um aumento de $30 \%$ nos sintomas de depressão já nos primeiros 30 dias de isolamento social (XIE X, et al., 2020). Já em relação ao Transtorno de Estresse Pós-Traumático (TEPT), estudos realizados no contexto da pandemia por $\mathrm{H} 1 \mathrm{~N} 1$ indicaram que $30 \%$ das crianças submetidas ao isolamento social apresentam o transtorno em comparação àquelas que não haviam sido submetidas à medida de restrição 
(MEHERALI S, et al., 2021). Além de gerar impactos emocionais, TEPT afeta o desenvolvimento cerebral das crianças, de forma a aumentar a reatividade a ameaças e gerar fraca regulação emocional (GUESSOUM SB, et al., 2020)

Não obstante, impactos na saúde física e mental não são vivenciados da mesma forma pelas crianças. É plausível que vulnerabilidades psicossociais pré-existentes, como desvantagem socioeconômica, histórico de psicopatologias e vitimização infantil, amplifiquem os efeitos negativos do distanciamento social (DANESE A e SMITH P, 2020; GOSH R, et al., 2020).

Para os infantes, a escola representa um local de aprendizagem, bem como proporciona liberdade, interação com pares, noções de higiene e alimentação saudável. Mais do que isso, para crianças que vivem em países em desenvolvimento e subdesenvolvidos, a escola é o local que propicia suporte nutricional (GHOSH R, et al., 2020).

Segundo o Fundo de População das Nações Unidas (UNFPA) (2020), com o fechamento dos centros educacionais, 370 milhões de crianças ficaram sem acesso aos alimentos oferecidos pelas escolas, fato que intensifica ainda mais o cenário de insegurança alimentar. Somando-se a isso, a piora do cenário econômico faz com que crianças de famílias de baixa-renda passem a exercer algum tipo de atividade remunerada para ajudar na geração de receita, o que contribui para o aumento das taxas de trabalho infantil e abandono escolar. Haverá também aumento dos casos de exploração sexual e prostituição, como experenciado durante a epidemia de Ebola em 2014 (GHOSH R, et al., 2020). Ademais, a redução de renda foi apontada como principal fator responsável pelo desenvolvimento de transtornos de cunho psicológico após a recuperação do surto de SARS em Beijing, China, em 2003 (GUESSOUM SB, et al., 2020).

O fechamento de escolas especiais e centros de cuidado afeta a rotina e o desenvolvimento de crianças portadoras de transtornos mentais. O transtorno do espectro autista, por exemplo, apresenta condições concomitantes, tais como, depressão, ansiedade e Transtorno de Déficit de Atenção e Hiperatividade (TDAH). Assim, a falta de interação com pares e de oportunidades de aprendizado e desenvolvimento podem resultar em regressão do quadro, aumento de problemas de comportamento e lesões autoprovocadas (SINGH S, et al., 2020).

A adolescência, por sua vez, é um período marcado por elevada sensibilidade emocional e necessidade constante de interação com pares (ORBEN A, et al., 2020). O distanciamento social durante a pandemia provocou o rompimento dessas interações e expôs os adolescentes a inúmeros fatores de risco para psicopatologias, como: incerteza sobre o futuro, mudança abrupta de rotina, doenças mentais dos pais, problemas financeiros, entre outros (DANESE A e SMITH P, 2020). Consequentemente, quadros de ansiedade, depressão, hiperatividade, aumento da agressividade e estresse pós-traumático são apenas alguns exemplos dos impactos psicossociais que serão experienciados a curto ou longo prazo (ORBEN A, et al, 2020).

Um estudo realizado com adolescentes e adultos jovens chineses revelou que 14,4\% já manifestavam sintomas de TEPT apenas 2 semanas após ter sido declarado estado de pandemia pela Covid-19 (LIANG L, et al., 2020). No que tange às questões emocionais, é estimado que meninas sejam mais propensas a apresentarem níveis de depressão e ansiedade mais elevados em comparação a adolescentes do sexo masculino durante a pandemia pela Covid-19. Além do mais, são duas vezes mais inclinadas a sofrer de transtorno de estresse pós-traumático (GUESSOUM SB, et al., 2020).

Nesse contexto, a internet tornou-se o único meio disponível para que os adolescentes não rompessem por completo as interações com pares. Apesar disso, a prolongada circulação em ambientes virtuais e a superexposição de si deixa os jovens vulneráveis à violência digital e autoinfligidas. A reprodução de desafios online, encontrados principalmente no YouTube, e revestidos em tom de "brincadeira" colocam em risco a saúde e a vida desses indivíduos (DESLANDES SF e COUTINHO T, 2020).

Se usados com moderação e supervisão parental, os meios de sociabilidade digital podem ajudar a mitigar alguns dos efeitos negativos do distanciamento social, como depressão, ansiedade e solidão (GHOSH R, et 
al. 2020; JÚNIOR PGF, et al., 2020; ALMEIDA CAN, et al., 2020). Todavia, nem todos os adolescentes possuem acesso a tecnologias digitais. Estudos apontam que meninas de famílias menos privilegiadas economicamente, em comparação aos meninos, possuem menor acesso a eletrônicos, o que pode prejudicar o acesso a plataformas digitais de ensino e até mesmo gerar evasão escolar (SINGH S, et al., 2020).

Um estudo canadense apontou o aumento do consumo de álcool e cannabis entre adolescentes durante a pandemia pela Covid-19 (JONES EAK, et al., 2021). A curto prazo, o uso de tais substâncias pode ajudar a lidar com questões emocionais, como desesperança, ansiedade, irritabilidade e pensamentos negativos. Porém, a longo prazo, os sintomas citados podem ser agravados e o uso de drogas pode se transformar em dependência (MEHERALI S, et al., 2021).

Crianças e adolescentes estão mais vulneráveis a psicopatologias e violências digitais e auto infligidas, por conta da exposição prolongada a estressores, redução de atividades físicas, superexposição nos meios de sociabilidade digital e a telas. Outros fatores relacionados a eventos negativos futuros na saúde mental, além do distanciamento social, são altas taxas de mortalidade, baixa disponibilidade de Equipamento de Proteção Individual (EPI's) e excesso de informações sobre a pandemia (QIN Z, et al., 2021).

Depressão, ansiedade, obesidade, distúrbios do sono, agressividade e estresse pós-traumático são algumas das consequências, a nível de saúde mental, que poderão ser vivenciados a curto e longo prazo por essas faixas etárias (GHOSH R, et al., 2020; JÚNIOR PGF, et al., 2020; ALMEIDA CAN, et al., 2020). No entanto, crianças e adolescentes que já experienciaram situações de vulnerabilidade, como relações negativas com pais e irmãos, cenário de insegurança alimentar, desigualdade social e histórico de psicopatologias, foram ainda mais afetados negativamente pelas medidas de distanciamento social (DANESE A e SMITH P, 2020; GOSH R, et al., 2020; ORBEN A, et al., 2020).

$\mathrm{Na}$ tentativa de minimizar os efeitos negativos do distanciamento, recomenda-se que pais e responsáveis equilibrem a rotina das crianças, agendando horários de estudo e tempo para brincar, evitando excessos de exposição a telas (LIMA RC, 2020). Ademais, Fundo das Nações Unidas para a Infância (UNICEF) e OMS sugerem que os responsáveis transmitam às crianças informações sobre a pandemia de forma clara e em linguagem compreensível, abrindo espaço para que elas possam expressar seus sentimentos e angústias (DESLANDES SF e COUTINHO T, 2020).

Em relação aos adolescentes, para suprir a diminuição de interação social com pares, a família deve criar maior vínculo com os jovens a partir de realização de atividades em conjunto, como jogos de tabuleiro, jogos virtuais com maior demanda física que os videogames tradicionais, entre outros. Intervenções psicoeducacionais para adolescentes e seus pais também devem ser implementadas, de modo a cuidar da saúde mental de ambos (DANESE A e SMITH P, 2020).

Por fim, as esferas governamentais possuem papel crucial na promoção de justiça social e equidade, as quais diminuiriam o abismo social entre crianças e adolescentes de países subdesenvolvidos e em desenvolvimento em relação àqueles privilegiados economicamente. Suporte financeiro às famílias de baixa renda será essencial para diminuir as taxas de abandono escolar, prostituição e trabalho infantis (GHOSH R, et al., 2020).

\section{CONSIDERAÇÕES FINAIS}

Diante da revisão efetuada, observa-se que crianças e adolescentes não são os principais agentes de adoecimento, embora sejam mais vulneráveis a impactos psicológicos que as demais faixas etárias. Estudos apontam a depressão, ansiedade e TEPT como algumas das psicopatologias a serem vivenciadas a curto e longo prazo. Em relação aos impactos físicos, pode-se citar a obesidade e os distúrbios do sono. Como sendo a primeira pandemia enfrentada pela humanidade no tempo online, pesquisas debatem sobre o papel ambíguo da Internet e dispositivos eletrônicos no enfrentamento da Covid-19. Assim, percebe-se a relevância da seguinte revisão para que se conheça a influência de pandemias, como a causada pela Covid-19, na vida de crianças e adolescentes e para que intervenções sejam tomadas a tempo. 


\section{REFERÊNCIAS}

1. ALMEIDA CAN, et al. COVID-19 and obesity in childhood and adolescence: a clinical review. Jornal de Pediatria,2020; 96(5): 546-558.

2. AQUINO EM, et al. Medidas de distanciamento social no controle da pandemia de COVID-19: potenciais impactos e desafios no Brasil. Ciência \& Saúde Coletiva, 2020; 25(1): 2423-2446.

3. DANESE A, SMITH P. Debate: Recognising and responding to the mental health needs of young people in the era of COVID-19. Child and Adolescent Mental Health, 2020; 25(3): 169-170.

4. DE SANCTIS V, et al. Coronavirus Disease 2019 (COVID-19) in adolescents: an update on current clinical and diagnostic characteristics. Acta Biomed, 2020; 91(2): 184-194.

5. DESLANDES SF, COUTINHO T. O uso intensivo da internet por crianças e adolescentes no contexto da COVID-19 e os riscos para violências auto infligidas. Ciência \& Saúde Coletiva, 2020; 25(suppl 1): 2479-2486.

6. FUNDO DE POPULAÇÃO DAS NAÇÕES UNIDAS (UNFPA). Coronavirus disease (COVID-19) preparedness and response, 2020. Disponível em: https://www.unfpa.org/sites/default/files/resource-pdf/COVID19_Preparedness_and_Response_-_UNFPA_Interim_Technical_Briefs_Maternal_and_Newborn_Health_23_March_2020_.pdf Acessado em: 05 de janeiro de 2022.

7. GHOSH R, et al. Impact of COVID - 19 on children: special focus on the psychosocial aspect. Minerva Pediatrica, 2020 ;72(3): 226-235.

8. GUESSOUM SB, et al. Adolescent psychiatric disorders during the COVID-19 pandemic and lockdown. Psychiatry Research, 2020; 291: 113264.

9. JONES EA, et al. Impact of COVID-19 on mental health in adolescents: a systematic review. International Journal of Environmental Research and Public Health, 2021; 18(5): 2470.

10. JÚNIOR PGF, et al. Isolamento social: consequências físicas e mentais da inatividade física em crianças e adolescentes. Revista Brasileira de Atividade Física \& Saúde, 2020; 25 : 1-2.

11. LIMA RC. Distanciamento e isolamento sociais pela Covid-19 no Brasil: impactos na saúde mental. Physis: Revista de Saúde Coletiva, 2020; 30(2): 1-10.

12. MACIEL EL, et al. COVID-19 em crianças, adolescentes e jovens: estudo transversal no Espírito Santo. Epidemiologia e Serviços de Saúde, 2021; 30(4):

13. MARTINS MM, et al. Clinical and laboratory characteristics of sars-cov-2 infection in children and adolescents. Revista Paulista De Pediatria, 2021; 39.

14. MEHERALI S, et al. Mental health of children and adolescents amidst COVID-19 and past pandemics: a rapid systematic review. International Journal of Environmental Research and Public Health, 2021; 18(7): 3432.

15. OBA J, et al. Gastrointestinal manifestations and nutritional therapy during COVID-19 pandemic: a practical guide for pediatricians. Einstein, $2020 ; 18: 1-8$.

16. OLIVEIRA WA, et al. A saúde do adolescente em tempos da COVID-19: scoping review. Cadernos de Saúde Pública, 2020;36(8).

17. ORBEN A, et al. The effects of social deprivation on adolescent development and mental health. The Lancet Child \& Adolescent Health, 2020; 4(8): 634-640.

18. QIN Z, et al. Prevalence and risk factors associated with self-reported psychological distress among children and adolescents during the COVID-19 pandemic in china. JAMA Network Open, 2021; 4(1) :e2035487.

19. SINGH S, et al. Impact of COVID-19 and lockdown on mental health of children and adolescents: a narrative review with recommendations. Psychiatry Research, 2020; 293: 113429.

20. ORGANIZAÇÃO DAS NAÇÕES UNIDAS PARA A EDUCAÇÃO, A CIÊNCIA E A CULTURA (UNESCO). Coalizão Global de Educação. Resposta da educação frente à COVID-19. Disponível em: https://pt.unesco.org/covid19/educationresponse/globalcoalition. Acesso em: 15 de fevereiro de 2022.

21. XIE X, et al. Mental health status among children in home confinement during the coronavirus disease 2019 outbreak in Hubei Province, China. Jama Pediatrics, 2020; 174(9): 898-900.

22. ZHOU SJ, et al. Prevalence and socio-demographic correlates of psychological health problems in Chinese adolescents during the outbreak of COVID-19. European Child \& Adolescent Psychiatry, 2020; 29(6): 749-758. 